O AUTOR

Izaías Almada

Escritor, argumentista e dramaturgo.

\title{
VENTURAS E DESVENTURAS DO TEATRO BRASILEIRO
}

\begin{abstract}
Abrir o debate sobre o teatro com intercâmbio entre novas e antigas consagradas experiências pode realimentar a qualidade de sua produção dramatúrgica
\end{abstract}

"Querido público, vamos! Busquem sem esmorecer! Deve haver uma saída, tem que haver!"

B. BRECHT.

A boa alma de Sezuan, Epílogo.

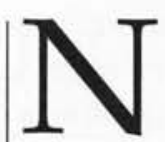

o segundo semestre do ano 2000, o Teatro Ágora, em São Paulo, com a supervisão do diretor Roberto Lage e do ator

Celso Frateschi, realizou um ciclo de palestras sobre teatro a que deu o nome de Odisséia do Teatro Brasileiro. Nessa viagem, realizada em duas semanas, além do jovem e entusiasmado público presente, participaram - como conferencistas - alguns dos mais credenciados ulisses das nossas artes cênicas. Entre eles, Gianni Ratto, Fauze Arap, Gianfrancesco Guarnieri, Fernando Peixoto, Augusto Boal, Zé Celso Martinez Corrêa e Antunes Filho.

Procurou-se, com esta iniciativa, contemplar ou dar a conhecer o que se faz atualmente em teatro pelo Brasil: de Norte a Sul do país. Mais do que isso foi conseguido. Entretanto, evidenciaram-se, du- rante o encontro, divergências e convergências entre esses já antigos mestres do teatro brasileiro em saudável confronto com as novas gerações, mas - sobretudo - ressurgiu a consciência (entre a maioria dos participantes) de que para o teatro retomar-se como sólido integrante do panorama cultural do país, será preciso, antes de mais nada, estudar e conhecer bem a realidade sobre a qual esse teatro trabalha. Ter dessa realidade uma leitura crítica e ampla, e do mundo à nossa volta um conhecimento mínimo necessário e satisfatório, um saber histórico sempre atualizado, que acabe - de uma forma ou de outra-por se manifestar sobre o palco. Não se trata aqui de medir quantitativamente a relação público/espetáculo, mas a qualidade e a sintonia entre o palco e a platéia.

Uma curiosa dicotomia se revelou durante esses encontros e que pode muito 
bem dar significado ao atual panorama do nosso teatro: o pessimismo dos mais velhos, permeado - contudo - por uma visão otimista e coletiva da superação de alguns dos obstáculos identificados, e o pessimismo dos mais jovens (exceção feita, no meu entender, a Sérgio Carvalho do Grupo Latão), permeado por uma visão individualista e/ou niilista da sua própria visão de mundo, como me pareceram as intervenções de Antônio Araújo, Eduardo Tolentino e Enrique Diaz, ainda voltados para questões meramente formais e/ou existenciais dentro dos grupos em que trabalham. Em outras palavras, o que isso quer dizer?

Quer dizer, antes de mais nada, que o fosso educacional e cultural provocado pelos anos de ditadura em nosso país e a nova realidade criada a partir desse buraco, e que tirou o norte de muita gente, tem que ser analisado, discutido e revisto em muitos de seus aspectos.

O Brasil precisa ser repensado pelas novas e antigas gerações e dessa união (síntese) iremos retomar os caminhos de uma arte universal, por se querer e se fazer autenticamente brasileira.

Arte é comunicação, mas nem toda forma de comunicação é arte. Conhecer uma coisa e outra é dever de todo artista e o artista é, antes de mais nada, um cidadão, um ser político. Não adianta querer identificar algumas mazelas e incertezas do teatro brasileiro contemporâneo sem entender o significado dessa passa- gem, dessa ruptura ideológica, que se fez entre os anos 60 e os anos 90, motivadora de novos caminhos, mas também de descaminhos e dúvidas. Ignorar esse aspecto é fazer a política do avestruz, é tapar o sol com a peneira...

\section{INDIVIDUALISMO: CADA UM NA SUA}

Os jovens brasileiros dos anos 60 não são, política ou artisticamente, melhores ou piores do que as gerações que lhes antecederam ou sucederam. Apenas tiveram condições e a acuidade necessária para sentir e interpretar o momento histórico em que viviam. Momento consubstanciado, entre outros fatores, na derrota do nazi-fascismo na Europa e na alternativa do socialismo revolucionário. Juntaram-se às inúmeras vozes que se ouviam por toda parte, conclamando-os à luta pela valorização do homem (falava-se mesmo na criação de um novo homem), pelas lutas de libertação nacional (partiçularmente na África e na América Latina), pela emancipação feminina, pelo rompimento de dogmas e estruturas fechadas de pensamento, pela alternativa do socialismo e pela paz no mundo. Apesar do recente fim de uma guerra mundial, a humanidade ainda se envolvia em muitos conflitos, localizados por quase todos os continentes: Coréia, Vietnã, guerrilhas na América do Sul, lutas anti-colonialistas na África. A China, em 1949, e Cuba, dez anos depois, deixaram o mundo capitalista, Ocidental e cristão, com os cabelos em pé e as barbas de molho. A guerra fria tornou-se mais quente do que nunca. E, é claro, tudo isso teve repercussões no Brasil. A tal ponto que o pensamento reacionário e conservador 
caboclo resolveu dar um basta ao avanço das novas idéias e rompeu com o convívio democrático entre nós. Como toda arte é política, mesmo aquela que nega esse enunciado, era natural que tudo o que cheirasse a socialismo, humanismo cristão ou socialista, solidariedade de classe, emancipação de direitos, coletivismo fosse combatido pelo pensamento repressivo que tomou conta do país. Pensamento este que já trazia a semente de um impiedoso individualismo. Fazer a cabeça, foi a tradução quase que literal para o make your mind dos americanos. A imprensa, a televisão e a escola contribuíram para fazer a nossa cabeça ${ }^{1}$.

O teatro sofreu, durante os anos 60 e 70, perseguições, invasões de espetáculos, censura e a prisão de muitos de seus atores, autores, técnicos e diretores. O teatro criou um bolsão de resistência e desobediência civil.

Com perspicácia e habilidade, o governo discricionário, o sistema, percebeu que precisava ter a hegemonia da informação para controlar o pensamento e evitar estas e outras manifestações de oposição. Fechou ou criou condições para que se fechassem jornais, editoras; censurou o noticiário; interveio nas Universidades, promoveu reformas de ensino de acordo com seus interesses e, num golpe final, incentivou a criação de uma Empresa Brasileira de Telecomunicações e de uma rede nacional de televisão, ao mesmo tempo cativa e interessada em defender um Estado autoritário. Aqui, os interesses e os privilégios se confundiram.

\section{TEATRO E TELEVISÃO}

Um tema recorrente entre os palestrantes da Odisséia do Teatro Brasileiro foi a televisão. Embora sempre se tenha tomado o cuidado de preservar o veículo (o meio), ficou muito difícil deixar de apontar alguns estragos provocados pela televisão ao teatro brasileiro a partir dos anos 70 . O sucesso popular imediato e os grandes salários advindos das enormes verbas publicitárias foram o canto da sereia para muitos de nossos atores e autores. Mas esta é apenas a ponta do iceberg. À força de invadir milhões de lares brasileiros todas as noites, num país de grande contingente de analfabetos e semi-analfabetos, a televisão acabou por criar uma nova estética e uma nova dramaturgia para produtores e consumidores de drama, real ou ficcionado. Se o telejornal expunha as vísceras do drama real, tornava-se necessário glamourizar o drama ficcionado. Se o país real é pobre e analfabeto, mas emergente e em desenvolvimento, será preciso mostrar que - apesar dos conflitos e das fortes contradições sociais, da luta de classes que caracterizam esta realidade - o convívio entre pobres e ricos não é tão complicado assim, desde que os pobres e ricos honestos estejam sempre prontos a lutar contra os ricos 
e pobres desonestos. O problema do homem está dentro dele e não nos conflitos e nas injustiças sociais.

Uma condição não exclui a outra, mas a partir dessa dramaturgia edulcorada, com raríssimas exceções para uma ou outra telenovela ou minissérie, o país passou a entender de outra maneira a sua narrativa dramática: a dramaturgia do farinha pou$\mathrm{ca}$, meu pirão primeiro, do salve-se quem puder. Claro, com reflexos imediatos nas novas gerações de autores, atores e diretores não só de televisão, mas também de cinema e de teatro ${ }^{2}$.

O cinema sucumbiu em finais da década de 70 para só dar sinais de vida nos últimos cinco anos, assim mesmo deixando a desejar quanto a novas propostas, mesmo que apenas estéticas. E, vejam só, apresentando uma dramaturgia calcada na estrutura da telenovela e também no uso de atores de reconhecido sucesso em televisão! E o teatro não ficou atrás. Além de criar o besteirol, nome sugestivo para quem não tem nada a dizer sobre o palco (apesar de alguns poucos e excelentes trabalhos no gênero), o teatro foi - muito em função das necessidades do mercado produtor e consumidor de telenovelas - tentando se adaptar a uma nova realidade: a mudança de horários na apresentação dos espetáculos (para que o público não perdesse os finais de novelas ou capítulos importantes); a diminuição dos dias de representação nos teatros (há espetáculos que atualmente só se apresentam de sexta-feira a domingo, quando há alguns anos as apresentações eram de terça-feira a domingo, com oito espetáculos semanais), isto para atender aos dias e horários de gravação das novelas; as academias de musculação e desfile de moda substituindo as escolas de preparação de atores, o close-up e o plano americano substituindo a noção de espaço cênico e o conhecimento do próprio corpo ${ }^{3} ; \mathrm{o}$ mundanismo e a coluna social substituindo Shakespeare e Nélson Rodrigues, aqui tomado como qualidade de dramaturgia e não como inspirador de fatias dramatizadas do cotidiano.

Com tal quadro de referência, levandose em conta apenas o fenômeno televisivo, não devemos ficar espantados com a queda de qualidade da nossa produção teatral. Queda de qualidade que se infere estatisticamente na opinião dos que fazem teatro há pelo menos trinta anos em centros como Rio de Janeiro e São Paulo.

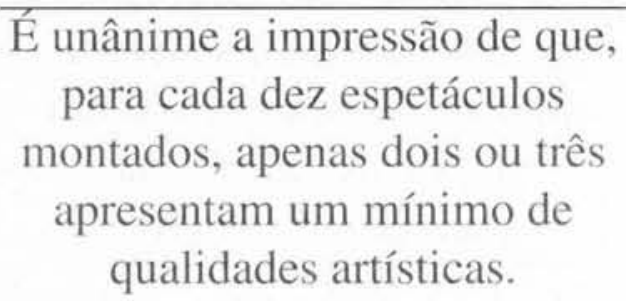

Considera-se aqui os principais fundamentos que se tornam necessários para a produção de um bom espetáculo teatral: qualidade do texto, estrutura do enredo, nível de interpretação, direção segura e criativa, domínio do espaço cênico, uso de luz e som (música) adequados à pro-

\section{RIDENTI, Marcelo. Em busca do... op. cit.}

3. A existência de uma ou mais câmeras para a captação das imagens das telenovelas obriga os atores a se preocuparem mais com as suas expressões de rosto e/ou com movimentos da cintura para cima, num tipo de representação mais contido, onde muitas vezes não se requer nem voz apropriada, trabalhada. Voz, corpo e máscara se reduzem às necessidades dos primeiros planos. 


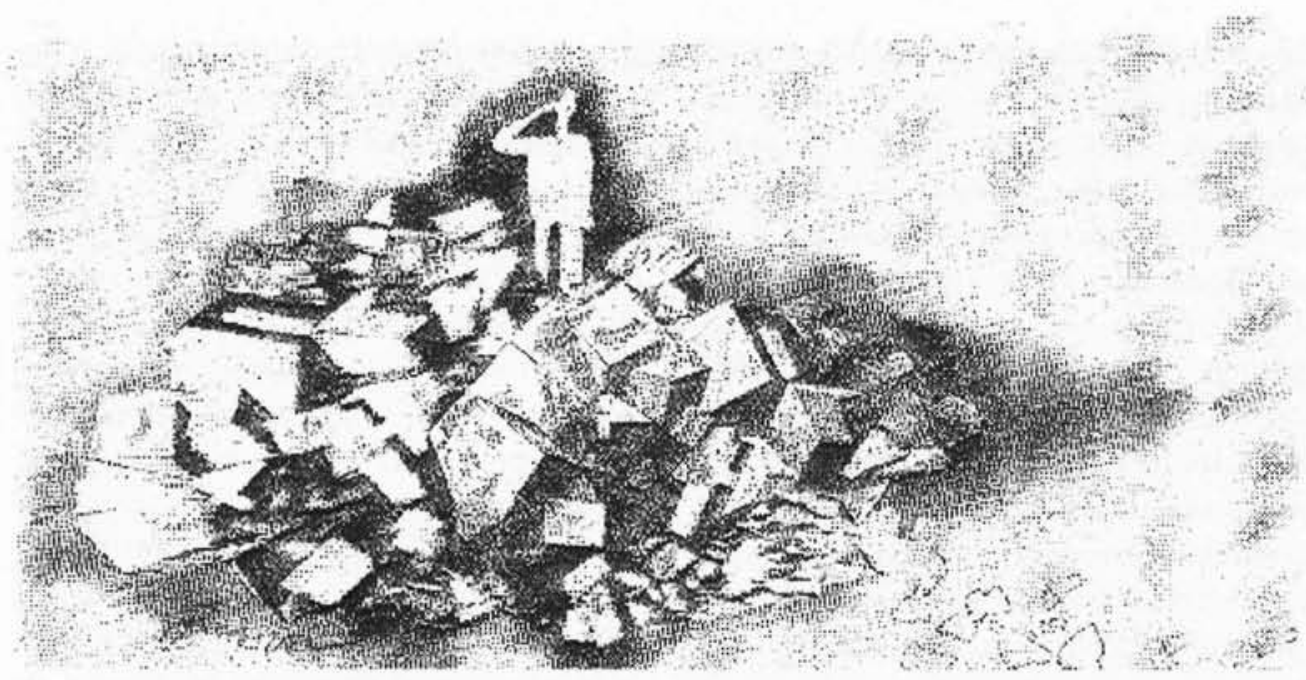

Mariza Dias Costa

posta estética apresentada ${ }^{4}$.

Nunca é demais lembrar que em momentos de estagnação ou retrocesso cultural é, por vezes, significativo o aumento do número de novas experiências estéticas, de novos caminhos e pesquisas. No nosso caso, as várias propostas da descoberta do corpo e do espaço ou da tentativa de entender a falta de comunicação e isolamento do ser humano (o excesso de individualismo visto aqui como característica inerente ao ser humano e não como decorrência de uma pressão econômica e social), sem levar em conta a realidade que o cerca; ou ainda ligeiras comédias de costumes, experiências em sua maior parte que procuraram esconder a falta de idéias ou escamotear o próprio vazio cultural em que se viveu ou ainda se vive nesse país de grandes golpes financeiros, espertezas políticas e descaso pelo cidadão. São as chamadas estéticas da minhoca (corpo) ou do vácuo (uso do espaço), ou ainda minimalistas (ressaltando-se aqui o bor- dão da incomunicabilidade do ser humano), bastante valorizadas nos anos 80 . Como minhoca não pensa e idéias não se propagam no vácuo, muitas dessas experiências são logo esquecidas e pouco contribuem para a valorização da nossa cultura teatral.

Some-se a isso o advento do marketing cultural, eufemismo que no Brasil procura, entre outros interesses, dissimular uma censura à livre criação artística, criando a figura do atravessador no mercado das artes.

A televisão passou também a contribuir perversamente com a seleção natural, por parte do público, na escolha das peças a que se vai assistir.

O fenômeno se dá da seguinte maneira: uma novela (de preferência no horário nobre) consegue a audiência de 60 milhões de

4. PALLOTTINI, Renata. Dramaturgia: construção do Personagem. São Paulo: Ática, 1989. 
espectadores por noite: o elenco de suporte da novela adquire (ou aumenta) sua popularidade, incluindo-se aqui os anúncios publicitários de ocasião, as capas de revistas, entrevistas em todos os órgãos de informação etc. Alguns desses atores preparam seus projetos de teatro e vão atrás das verbas de patrocínio, oportunisticamente, sempre mais fáceis de se conseguir quanto mais conhecido o ator (é preciso esclarecer que muitos projetos que não contam com alguns nomes de sucesso, sequer são apreciados pelos chamados departamentos de marketing cultural das empresas). A esse propósito, aliás, e numa atitude de dignidade e respeito pelo teatro e por seus colegas de profissão, $\mathrm{o}$ ator Raul Cortez publicou na Folha de S. Paulo (agosto/2000) um notável, lúcido e corajoso artigo a respeito da questão, pouco antes de estrear a sua montagem de Rei Lear, reconhecendo o privilégio que alguns atores como ele têm para produzir seus próprios espetáculos.

Num dos debates que se seguiram às palestras da Odisséia, o ator Antônio Fagundes - homem de teatro e televisãoargumentou que essa situação de privilégios para os que são ídolos de telenovelas não exprime a realidade do mercado, alegando que em sua última montagem, mesmo com patrocínio de uma grande empresa, ele tinha conseguido apenas a presença de pouco mais de cem mil espectadores. Pareceu-me que - além de confrontar-se com a opinião de Raul Cortez, seu colega em dois dos mais recentes sucessos do horário nobre, o fato de Fagundes ter levado cem mil espectadores ao teatro em seis meses de representação em São Paulo é - nos dias que correm - uma façanha que a maioria dos outros grupos e espetáculos não conse- guem. Façanha essa, repito, graças à popularidade e ao sucesso televisivo de Fagundes que, por enfrentar dificuldades de outra ordem, ainda assim não conseguiu sustentar a sua companhia de teatro de repertório, uma das mais bem sucedidas experiências de se conquistar um público através de um repertório de qualidade nos últimos anos... Mas, apesar de Fagundes e outros de seus colegas de formação teatral inconteste, quando uma sociedade passa a quantificar e confundir o sucesso e o esteticamente bom a partir dos pontos do ibope, alguma coisa vai mal. Não erro em afirmar que os teatros de Londres, Nova Iorque e Paris estão sempre de casa cheia e boa parte dos seus atores sequer são conhecidos na televisão ou mesmo no cinema.

\section{GOSTO POPULAR}

Já está mais do que na hora de refletirmos sobre a falácia de um argumento que se tornou emblema da baixa qualidade artística e temática, não só do nosso teatro, mas também da televisão, da música popular e do cinema (em menor escala) feitos no Brasil a partir dos finais dos anos 70. Aquele argumento que diz não ser melhor o nível artístico e cultural dessas produções porque "se faz aquilo que o público gosta, que o povo quer". O que se quer é transferir para o chamado gosto popular boa parte da preguiça, da falta de critérios ou mesmo da falta de conhecimento e suporte necessários para a elaboração de um trabalho mais apurado.

Ou dissimular-se, com tal assertiva, alguma censura estética e mesmo ideológica. Ou ainda, uma simples tentativa de justificar a própria sobrevivência como 
trabalhador das artes. Qualquer destas hipóteses pode não responder individualmente a questão, mas juntas formam um quadro bastante explicativo daquilo que acontece com a televisão, o teatro, a música popular no Brasil.

Prova de que é possível, em teatro, superar parte do problema é o trabalho de Juca de Oliveira, Marcos Caruso e Jandira Martini, por exemplo, que acabaram por criar uma dramaturgia de crítica imediata a muitas de nossas mazelas, um olhar impiedoso, e ao mesmo tempo, humano sobre o Brasil pós anos 70, com graça e inteligência, sempre lotando os teatros onde suas peças são apresentadas. Contudo, se o exemplo tem frutificado na comédia, o mesmo não se dá no drama ou na tragédia, onde nossos novos autores não parecem dispostos a meter a mão na cumbuca. A dramaturgia brasileira contemporânea ainda não se debruçou sobre o país que sobrou dos anos $60 / 70$ e que procura renascer a partir de uma democracia ainda tosca e fortemente enquadrada dentro de interesses mercantilistas e conservadores.

$\overline{\text { Uma dramaturgia que não ousa, }}$ não investiga, não denuncia.

O próprio governo, a partir do nefasto Collor de Melo, tem tentado transferir cada vez mais a questão cultural para a iniciativa privada, o que não seria de todo mal se nossos empresários fossem um pouquinho mais cultos e os atravessadores não tivessem o olho maior que a barriga. Contudo, essa política cultural tem tam- bém contribuído para transformar o sucesso financeiro de público num indicador da qualidade dos espetáculos, o que é inteiramente falso e subjetivo, mesmo vistas as coisas em termos de mercado, para usar uma expressão ao gosto atual.

\section{QUALIDADE DRAMATÚRGICA}

Pode até ser que em algumas gavetas ou memórias de computador estejam escondidas algumas peças de inegável qualidade. Por vezes são apresentadas em leituras públicas. Mas quem está interessado em encená-las? Ou patrocinálas? Há todo um conjunto de fatores, alguns apontados neste artigo, que contribuem hoje no Brasil para pôr em dúvida a eficácia de determinada dramaturgia, particularmente aquela voltada para o conhecimento mais visceral do homem e da sociedade brasileira contemporânea. Futebol, corrupção, reforma agrária, Aids, drogas, desintegração familiar, o papel da informação e da mídia em geral, a periferia das grandes cidades, o desemprego e os conflitos humanos daí advindos, a discussão sobre a violência, a proliferação de igrejas e religiões... Onde estão estes temas no nosso teatro contemporâneo? Não temos autores que possam escrever com propriedade sobre eles? É claro que te$\mathrm{mos}^{5}$. Mas talvez se esteja partindo do princípio de que estes temas não despertarão o interesse do público ou não farão uma boa bilheteria, porque o público já tem uma vida muito difícil e quer ir ao teatro para se divertir, dar umas boas risadas. 
O desafio é grande, mas há sempre uma possibilidade de superá-lo. O lixo cultural consumido diariamente pelo público brasileiro já nos autoriza supor, ao contrário dos que se vêm alimentando com a produção desse lixo, de que há uma razoável indigestão a ser combatida e de que é possível encontrar os anticorpos

Resumo: $\mathrm{O}$ artigo trata de crítica à atual produção teatral brasileira. A partir do evento Odisséia do Teatro Brasileiro, que reuniu alguns dos mais importantes nomes do teatro, o autor confronta a situação do teatro nos anos 60 e $70 \mathrm{com}$ a atual. Discute como a televisão e as regras de mercado publicitário têm pautado as produções, bem como critica a mesmice e a falta de empenho dos interessados em buscar maior qualidade dramatúrgica inspirados na realidade brasileira.

Palavras-chave: teatro brasileiro, televisão, anos 60 , realidade brasileira, dramaturgia para a defesa do organismo social. Seja no teatro ou fora dele. Bertolt Brecht, mesmo sob o nazismo, foi capaz de criar uma obra e uma teoria teatral das mais sólidas dentro do teatro contemporâneo, num exemplo de resistência ao arbítrio e à mediocridade. Um exemplo a ser sempre lembrado.

(Brazilian theater adventures and misfortunes)

Abstract. The article deals with the critique of the current Brazilian theater production. Starting from the Odisséia do Teatro Brasileiro event, which gathered a few of the most important names in the theater, the author confronts the theater situation in the 1960's and 1970 's with the current situation. He discusses how the television and the advertising market rules have guided the productions, and criticizes the continual repetition and lack of dedication of those who are involved in the area to search for greater dramaturgical quality inspired in the Brazilian reality.

Key words: Brazilian theater, television, the 1960 's, Brazilian reality, dramaturgy 